University of Nebraska - Lincoln

DigitalCommons@University of Nebraska - Lincoln

\title{
Microbial Decontamination and Weight of Carcass Beef as Affected by Automated Washing Pressure and Length of Time of Spray
}

\author{
John D. Crouse \\ U.S. Meat Animal Research Center \\ Maynard E. Anderson \\ University of Missouri - Columbia \\ H. Donald Naumann \\ University of Missouri - Columbia
}

Follow this and additional works at: https://digitalcommons.unl.edu/hruskareports

Part of the Animal Sciences Commons

Crouse, John D.; Anderson, Maynard E.; and Naumann, H. Donald, "Microbial Decontamination and Weight of Carcass Beef as Affected by Automated Washing Pressure and Length of Time of Spray" (1988).

Roman L. Hruska U.S. Meat Animal Research Center. 97.

https://digitalcommons.unl.edu/hruskareports/97

This Article is brought to you for free and open access by the U.S. Department of Agriculture: Agricultural Research Service, Lincoln, Nebraska at DigitalCommons@University of Nebraska - Lincoln. It has been accepted for inclusion in Roman L. Hruska U.S. Meat Animal Research Center by an authorized administrator of DigitalCommons@University of Nebraska - Lincoln. 


\section{Microbial Decontamination and Weight of Carcass Beef as Affected by Automated Washing Pressure and Length of Time of Spray}

John D. Crouse, Maynard E. Anderson, and H. Donald Naumann'

\section{Introduction}

Carcass beef has traditionally been washed by hand to remove foreign material such as hair, soil particles, and microbiological organisms that have contaminated the surfaces. These carcasses are inspected by the Food Safety Inspection Service (FSIS) to detect defects related to carcass cleanliness. Recent research and development of technology have emphasized automated machine washing.

At pressures above that normally used, it is conceivable that water could penetrate tissue surfaces and be absorbed by the carcasses. Also, longer wash periods may enhance water uptake by carcasses. According to the ASHRAE Handbook and Product Directory, the average shrinkage of carcass beef using good current practices was $1.3 \%$ at $20 \mathrm{hr}$ postmortem. USDA meat inspection regulations required that carcasses sustain no net increase in weight due to absorption of water during the washing process. There is no available literature on the effects of various automated washing techniques on carcass weights after a $20-\mathrm{hr}$ chill.

The objectives of the study reported presently were to determine the effects of nozzle pressure and length of time washed on the microflora and weights of carcass beef at $20 \mathrm{hr}$ postmortem.

\section{Procedure}

Material and design. Carcasses were obtained from 56 heifers that were fed a corn-corn silage diet. Heifers were slaughtered, dressed, and carcasses split by normal commercial procedures. Carcasses were skinned by knife while on the rail without the use of an automated hide puller. Sides were not shrouded after washing. Sides were assigned randomly to a $3 \times 2$ split-plot experiment. Sides were washed with water at slow $(15 \mathrm{ft} / \mathrm{min})$, medium (20 ft/min), or fast $(25 \mathrm{ft} / \mathrm{min})$ chain speeds (CS) through an automated carcass washer. Sides within carcasses were assigned to low pressure ( $350 \mathrm{psi}$ ) or high pressure (600 psi) water spray wash (SP). Carcasses were stored in a $32^{\circ} \mathrm{F}$ cooler during the study.

Washing. Sides passed through a chamber between two spray bars that oscillated on a vertical axis of $45^{\circ}$. The spray bars were opposite each other, and each possessed nine locations for single or double nozzles. Nozzles of opposite bars were 25 inches apart. (Nozzle sizes and locations and a description of the chamber is provided in detail by Anderson et al.) Carcass sides were weighed before washing, 5 min after washing, and $20 \mathrm{hr}$ after washing using on-rail scales.

Microbiology. A random subsample of equal number of right or left sides from 36 carcasses was used to enumerate microorganisms before washing and $20 \mathrm{hr}$ after washing. After treatment ( $20 \mathrm{hr}$ postmortem), carcasses were sampled from locations adjacent to location of initial sampling. A sterile template (15 in) was used to

Crouse is the research leader, Meats Unit, MARC; Anderson is with ARS, USDA, Eckles Hall, University of MissouriColumbia; Naumann is with the Department of Food Science and Nutrition, University of Missouri-Columbia. define the sample area. Two adjacent samples were taken from the round over the Biceps femoris muscle, and two adjacent samples were taken from the forequarter over the Longissimus muscles adjacent to the first through fifth thoracic vertebrae. Sterile forceps and scalpel were used to remove tissue samples .2 in deep.

Tissue from both 15-in sample sites within the forequarter or hindquarter were placed in a stomacher bag containing $100 \mathrm{ml}$ of $0.1 \%$ peptone diluent, top sealed by heat, placed in an ice chest, and transported within $8 \mathrm{hr}$ to the laboratory for serial dilution, plating, and incubation.

Violet red bile agar with glucose was used to enumerate Enterobacteriaceae. Aerobic microorganisms were enumerated on standard plate count. Samples were plated at appropriate dilutions, and counts were made according to Standard Methods for the Examination of Dairy Products, except for incubation temperatures. Standard plates and violet red bile plates were incubated at $95^{\circ} \mathrm{F}$ for 48 and $24 \mathrm{hr}$, respectively.

Carcass observations. After holding $24 \mathrm{hr}$ at $32^{\circ} \mathrm{F}$, carcasses were evaluated for quality and yield grade factors by USDA procedures (Table 1). Average carcass weight

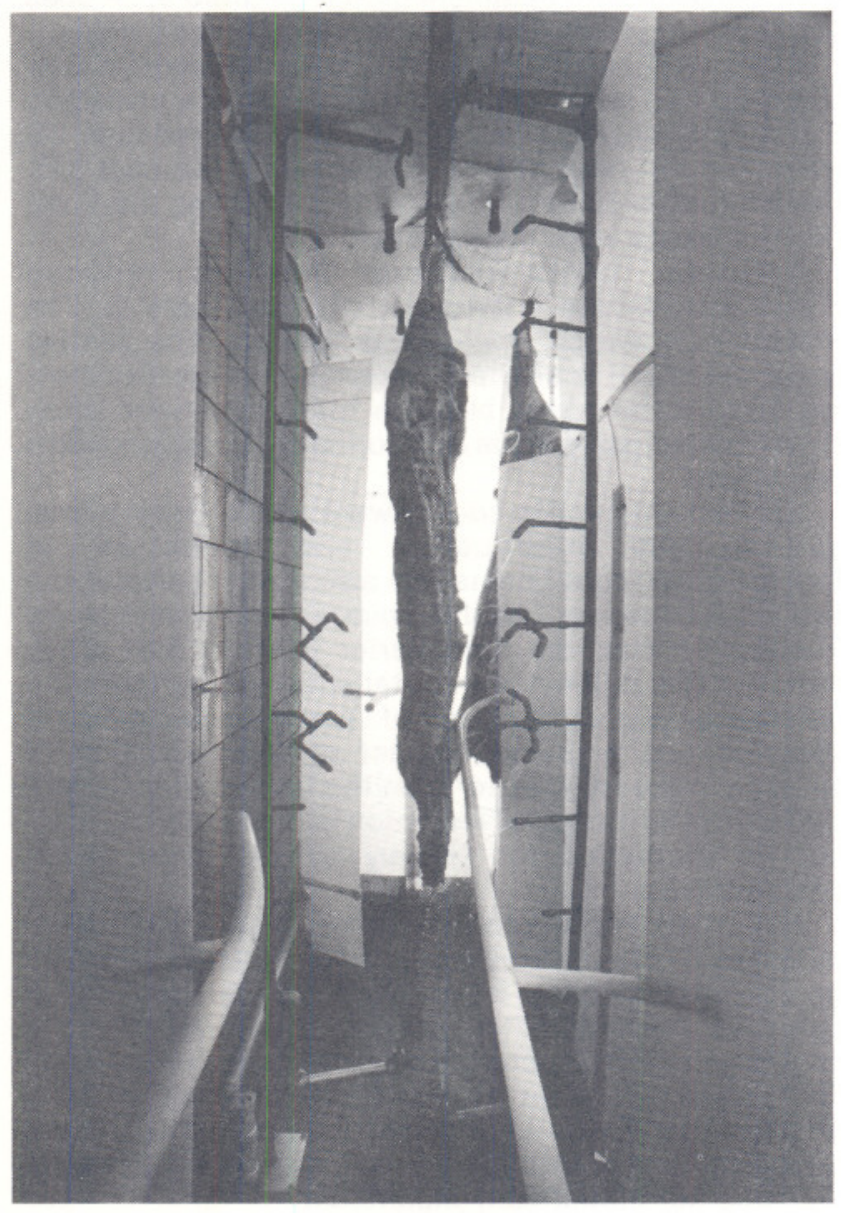

Automated carcass washer. 
was $643 \mathrm{Ib}$. Marbling (small ${ }^{10}$ ) and maturity $\left(A^{45}\right)$ scores indicate that carcasses were typical of those grading low USDA Choice. Carcasses also possessed 0.34 in fat thickness over the longissimus muscle at the 12th rib.

Data analyses. Data were analyzed by least-squares procedures. Variation in weight due to treatments was examined by analyzing differences between weights before washing and weights 5 min after washing or weights $20 \mathrm{hr}$ after washing. Similarly, variation in the microbial contamination due to treatments was examined by analyzing differences in plate counts obtained from samples before treatment with plate counts from samples obtained after treatment. Data on microbiological counts were expressed in logs to the base 10. Main effects and 2-way interactions were fitted to the model. Preliminary analysis indicated that 3-way interactions were not important sources of variation.

\section{Results}

Carcass weight. Interactions of SP by CS were not important sources of variation in side wt. Weights of sides were similar at high or low SP at all three CS treatments. Side weights before, $5 \mathrm{~min}$ after, and after $20 \mathrm{hr}$ of storage are given in Table 2. Sides gained $1.8 \mathrm{lb}(0.57 \%)$ in wt during washing. However, the gain in side wt plus an additional $3.3 \mathrm{lb}(1.04 \%)$ was lost during the 20 -hr storage period.

Variation in change (before washing - after washing) of side wt due to SP are given in Table 3. Sides washed with high SP gained more than sides washed with low SP (2.0 vs $1.6 \mathrm{lb})$. After $20 \mathrm{hr}$ of storage, weights of sides were similar in both treatment groups. Therefore, SP does not have long-term effects on water uptake of sides.

Sides washed with the slow CS gained more wt than sides washed with the medium CS 5 min after washing (Table 4). Similarly, sides washed with the medium CS were heavier than sides washed with the fast CS. However, after $20 \mathrm{hr}$ of storage, sides among the three CS treatments were similar in wt.

Bacterial contamination. Washing reduced Enterobacteriaceae counts by $1.52 \mathrm{log}$ (Table 2). The reduction in aerobic counts was $0.87 \mathrm{log}$. The aerobic count reduction is similar to previous observations using a tap water wash, but less than reductions when short-chain organic acids or chlorine are used as sanitizing agents.

Enterobacteriaceae counts were similar for the forequarter and hindquarter and reduction in Enterobacteriaceae counts was also similar between the two areas. However, aerobic counts were greater in the forequarter than the hindquarter (5.44 vs 5.29 logs). Although this difference was statistically significant, the difference was not likely of practical importance. Washing had a greater impact on the reduction of bacteria in the forequarter than the hindquarter (1.13 vs 0.68 logs). The increased reduction in the forequarter cannot be accounted for entirely by the larger initial contamination.

Reduction in Enterobacteriaceae counts was not affected by SP (Table 3). However, a trend in greater reductions in aerobic counts was observed for the low-SP compared to the high-SP treatment. Enterobacteriaceae counts or aerobic bacteria counts were not affected by CS (Table 4). Means for the slow CS indicated a possibility of greater reduction of Enterobacteriaceae than means for the medium or fast CS; however, this increased reduction was not statistically significant.

Research on carcass decontamination presently reported indicates that the pressure of water spray between 350 to 600 psi and speed of chain between 15 to $25 \mathrm{ft} / \mathrm{min}$ had no residual effect on water uptake of the carcass after $20 \mathrm{hr}$. Also, any combination of these pressures and chain speeds will make reductions in bacterial contamination. Forequarters possess greater contamination than hindquarters, but washing the carcass eliminates the differential in number of organisms. Additional research is needed to determine the effects of nozzle size or configuration. Variation in nozzles may affect water droplet size, water uptake by the carcass, and decontamination.

Table 1-Characteristics of carcasses used in carcass washing study

\begin{tabular}{lc}
\hline Trait & Mean \\
\hline Liveweight, Ib & 1,015 \\
Hot carcass wt, Ib & 643 \\
Fat thickness, in & .34 \\
Longissimus muscle area, in ${ }^{2}$ & 12.47 \\
Kidney, pelvic, and heart fat, \% & 3.0 \\
Marblinga & 410 \\
Maturityb & 145 \\
\hline${ }^{a}$ Marbling was scored: Slight- (300) to slight + (399), small- (400) to small + (499), \\
etc. ${ }^{\circ}$ Maturity was scored: A- (100) to A + (199).
\end{tabular}

Table 2-Variation in change in side wt and reduction in Enterobacteriaceae counts and aerobic counts by spray pressures

\begin{tabular}{lcc}
\hline & \multicolumn{2}{c}{ Pressure } \\
\cline { 2 - 3 } Trait & Low & High \\
\hline Change in wt, Ib: & 58 & 54 \\
No. & 1.60 & 2.07 \\
$5 \mathrm{~min}$ & -3.33 & -3.36 \\
$20 \mathrm{hr}$ & & \\
& & \\
Bacterial counts, log: & 36 & 36 \\
$\quad$ No. & 1.51 & 1.54 \\
Enterobacteriaceae & 0.99 & 0.77 \\
Aerobic & & \\
\hline
\end{tabular}

Table 3-Variation in change in side wt and reduction in Enterobacteriaceae counts and aerobic counts by chain speeds

\begin{tabular}{lccc}
\hline & \multicolumn{3}{c}{ Chain Speed } \\
\cline { 2 - 4 } Trait & Slow & Medium & Fast \\
\hline Change in wt, Ib: & 38 & 38 & 36 \\
No. & 2.10 & 1.83 & 1.58 \\
$5 \mathrm{~min}$ & -3.38 & -3.34 & -3.32 \\
$20 \mathrm{hr}$ & & & \\
Bacterial counts, log: & & 21 & 21 \\
$\quad$ No. & 21 & 1.48 & 1.46 \\
Enterobacteriaceae & 1.65 & 0.71 & 0.90 \\
Aerobic & 1.02 & &
\end{tabular}

Table 4-Enterobacteriaceae and aerobic counts by locations and reduction

\begin{tabular}{lcc}
\hline \multirow{2}{*}{ Trait } & \multicolumn{2}{c}{ Location } \\
\cline { 2 - 3 } & Forequarter & Hindquarter \\
\hline Enterobacteriaceae, log: & & \\
$\quad$ Before & 5.75 & 5.70 \\
$\quad$ Reduction & 3.48 & 3.26 \\
Aerobic, log: & & \\
$\quad$ Before & 5.44 & 5.29 \\
$\quad$ Reduction & 1.13 & 0.68 \\
\hline
\end{tabular}

